\title{
Social intelligence in 6-7-year-old children: features and application results of pedagogical diagnostics
}

\section{Inteligência social de crianças dos 6 aos 7 anos: características de diagnóstico pedagógico e resultados da sua aplicação}

\section{La inteligencia social de los niños entre 6 y 7 años: las características del diagnóstico pedagógico y los resultados de su aplicación}

\author{
Irina V. Sushkova1 ${ }^{1}$, Olesya N. Loshkareva ${ }^{1}$ id
}

${ }^{1}$ Bunin Yelets State University, Yelets, Russian Federation.

Corresponding Author:

Irina V. Sushkova

Email: irvisu15@mail.ru

How to cite: Sushkova, I. V., \& Loshkareva, O. N. (2021). Social intelligence in 6-7-year-old children: features and application results of pedagogical diagnostics. Revista Tempos e Espaços em Educação, 14(33), e16320.

http://dx.doi.org/10.20952/revtee.v14i33.16320

\begin{abstract}
The aim of the study is to identify the characteristics of social intelligence in children aged 6 to 7 years based on the development and application of appropriate diagnoses. Through methods of comparison, analysis, generalization, the concepts of "social intelligence of children from 6 to 7 years old", "pedagogical diagnosis of social intelligence of children from 6 to 7 years old" were developed. Modeling provided the creation of a model for the relationship between consciousness and social intelligence, the design made it possible to develop social intelligence diagnoses for children aged 6 to 7 years, and experience - its implementation. By the method of finding indicators of generalization, the results of the diagnosis of social intelligence of 110 children were obtained. Analysis, interpretation, and generalization allowed us to identify the characteristics of this diagnosis and the characteristics of results from its application. The concepts of "social intelligence of children aged 6 to 7 years", "pedagogical diagnoses of children aged 6 to 7 years", a model of the relationship between consciousness and social intelligence, social intelligence diagnoses of older preschoolers were developed. The characteristics of social intelligence of children aged 6 to 7 years and the corresponding diagnostic characteristics are revealed. The results of the study will allow planning of pedagogical work based on these characteristics.
\end{abstract}

Keywords: The structure of social intelligence. Self-regulation. Self-esteem. Interpersonal interaction. 6-7-year-old children. 


\section{RESUMO}

O objetivo do estudo é identificar as características de inteligência social de crianças dos 6 aos 7 anos com base no desenvolvimento e aplicação de diagnósticos adequados. Através de métodos de comparação, análise, generalização foram desenvolvidos os conceitos de "inteligência social de crianças dos 6 aos 7 anos", "diagnóstico pedagógico de inteligência social de crianças dos 6 aos 7 anos". Modelação proporcionou a criação dum modelo de relação entre consciência e inteligência social, o design tornou possível desenvolver diagnósticos de inteligência social de crianças dos 6 aos 7 anos, e a experiência - a sua implementação. Pelo método de encontrar indicadores de generalização, foram obtidos os resultados do diagnóstico de inteligência social de 110 crianças. Análise, interpretação, e generalização permitiram identificar as características deste diagnóstico e as características de resultados da sua aplicação. Os conceitos de "inteligência social de crianças dos 6 aos 7 anos", "diagnósticos pedagógicos de crianças dos 6 aos 7 anos", um modelo de relação entre consciência e inteligência social, os diagnósticos de inteligência social de pré-escolares mais velhos foram desenvolvidos. São reveladas as características da inteligência social de crianças dos 6 aos 7 anos e as características de diagnóstico correspondente. Os resultados do estudo permitirão planeamento de trabalhos pedagógicos com base nestas características.

Palavras-chave: Estrutura de inteligência social. Autorregulação. Autoestima. Interação interpessoal. Crianças dos 6 aos 7 anos.

\section{RESUMEN}

El propósito de esta investigación es identificar las características de la inte-ligencia social en los niños entre 6 y 7 años a partir del desarrollo y la aplicación del diagnóstico adecuado. Mediante los métodos de comparación, análisis y generalización se han desa-rrollado los conceptos de "inteligencia social en los niños entre 6 y 7 años" y de "diagnóstico pedagógico de la inteligencia social en los niños entre 6 y 7 años". El modelado ha proporcionado la creación de un modelo de relación entre la concien-cia y la inteligencia social, por su parte, el diseño ha contribuido al desarrollo del diagnóstico de la inteligencia social en los niños entre 6 y 7 años, mientras que el experimento ha determinado la implementación del proyecto. Mediante el método de búsqueda de indicadores de generalización, se obtuvieron los resultados de los diagnósticos de la inteligencia social de 110 niños. El análisis, la interpretación y la generalización han permitido identificar las características de este diagnóstico y las de los resultados de su aplicación. Se han desarrollado los conceptos de "inteligencia social en los niños entre 6 y 7 años", "diagnóstico pedagógico en los niños entre 6 y 7 años", se han elaborado un modelo de la relación entre la conciencia y la inteligencia social y se ha realiza-do el diagnóstico de la inteligencia social de los preescolares mayores. Se revelan las características de la inteligencia social en los niños entre 6 y 7 años y las carac-terísticas del diagnóstico correspondiente. Los resultados de la investigación per-mitirán planificar el trabajo pedagógico teniendo en cuenta estas características.

Palabras clave: Estructura de la inteligencia social. Autorregu-lación. Autoestima. Interacción interpersonal. Niños entre 6 y 7 años.

\section{INTRODUCTION}

The concept of 'social intelligence', introduced into scientific circulation in 1920 by Edward Lee Thorndike, has been studied to a certain extent in world science; however, nowadays it still remains a somewhat controversial issue. Psychologists and teachers are quite concerned on the issues of the essence of social intelligence, its characteristics, structure, and relationship with other types of intelligence and communicative competence, etc. The interpretation of its content has changed over time. The question of the structure of social intelligence underwent some extended discussion, revealing different approaches to the interpretation of the concept of 'social intelligence' and its structure; various reasons were employed to explain this phenomenon. For a 
long time, its measurement was conducted via verbal assessment (Savenkov, 2005), and the main attention was paid to cognitive characteristics (perception of other people, understanding of the motives of their behavior, behavioral aspects of social intelligence - all of that was identified via verbal measurements) (Savenkov, 2005). The discrepancy between the verbal assessment of one's social sphere and real behavioral characteristics made it possible to employ non-verbal methods of assessing social intelligence (Kosmitzki \& John, 1993). To the methodological problems of the study of social intelligence, I. Ruisel attributes the difficulties in defining this concept and differentiating social and academic intelligence, as well as the insufficiently differentiated position of social abilities in the context of human life (Ruisel, 1992).

Social intelligence is a factor that determines the top achievements of a person and the success of its self-realization (Sudneva, Karaulova \& Bogomaz, 2013). It provides for the formation of a behavioral model focused on social recognition, allowing successful socialization and social adaptation.

The scientific literature contains many attempts to determine the place of social intelligence in the structure of general intelligence (N. Kantor, J. Guilford) (Guilford, 1959; Cantor, 1987), create a periodization of its development (R. Selman, P. Erwin), (Erwin, 1993; Selman, 1980), develop a structure (S. Greenspan, J. Driscoll, R. Sternberg) (Greenspan \& Driskoll, 1997) and study the peculiarities of its development in children (O.V. Luneva, L.A. Varlamova, T.L. Shabanova, E.S. Zhurba, I.Yu. Isaeva, L.F. Fatikhova, A.A. Kharisova, I.V. Sushkova, O.N. Loshkareva and others) (Varlamova, 2016; Isaeva, 2011; Sushkova \& Loshkareva, 2019; Fatikhova \& Sayfutdiyarova, 2013; Fatikhova \& Kharisova, 2010; Shabanova \& Zhurba, 2019).

In the last twenty years, the attention of scientists has been given to the research of the relationship between social intelligence and general self-control (Slovas \& Cemanova, 2009); solving interpersonal situations as an indicator of social intelligence (Vasil'ova \& Vyrost, 2004); the ratio of gratitude, self-control, and social intelligence (Guilford, Morgan, \& Hemming, 2019); diagnostics of social intelligence (Silvera et al., 2001); measuring this phenomenon (Ushakov, 2004), professional characteristics of teachers' social intelligence and the influence of the educational managerial style on their social and emotional intelligence (Turker \& Tanriogen, 2019); the role of emotional intelligence and social competences of teachers in overcoming difficulties in working with students with special needs (Skura \& Swiderska, 2021); and the relationship between social intelligence, perceived antisocial (gang) behavior, and fear and stigmatization of primary and secondary teachers (Thorndike, 1920).

Several modern studies provide scientific information on the social intelligence of certain age groups of children: the influence of intelligence on the academic performance and well-being of adolescents (O'Connell \& Marks, 2021), and the relation between social intelligence of adolescents and their use of protective strategies (Maltes et al., 2012). Of particular consideration are the peculiarities of the social intelligence of children with developmental disorders (Hirosawa et al., 2020), and the intelligence and executive function of premature school-age children depending on birth weight and perinatal complications (Intelligence and executive function of school-age preterm children in function of birth weight and perinatal complication, 2021).

Recently, attention to the problem of the social intelligence of children in review has been highlighted through the prism of the early stages of ontogenesis. Some studies show that the child already in infancy shows some social intelligence in the form of understanding the actions and intentions of a person (Henderson et al., 2008). The connection is noted between the social intelligence of 4-year-olds with their mathematical-spatial abilities (Osterhaus et al., 2020) and the fact that preschoolers develop social and emotional competencies (Kruszewska, 2018), thuswise clearly presenting a specificity of social intelligence and creativity (Kosmitzki \& John, 1993). Of particular importance is a preschoolers' need for a communicative developing educational environment (Antopolskaya et al., 2017). O.Yu. Masyagina proposes to develop the structural 
components of social intelligence in preschool childhood by means of role-playing games, psychogymnastics, situation analysis, and creative team projects (Masyagina, 2010). Also, some studies have shown a connection between the moral choice of older preschoolers and manifestations of social intelligence in the form of motives for this choice (Sushkova et al., 2020).

Social intelligence is the basis for the development of positive children adaptation and socialization; therefore, it is essential to begin the development of social intelligence, which largely determines the outcome of this socialization, from the very preschool age. O.A. Burukina notes the modern revival of interest in the concept of 'social intelligence', the continuation of implicit theories of social intelligence, and the emergence of similar constructs such as 'emotional intelligence' and 'practical intelligence', but at the same time, the modern science still lack the broad and detailed prospect of opportunities for the development of social intelligence in different age periods of preschool childhood (Karvasarsky, 2007).

A special place in the development of social intelligence belongs to the period of senior preschool age, which features an intensive formation of the personality and the mechanisms of its behavior, along with a hierarchy of behavioral motives. Therefore, the importance of the study of the phenomenon of social intelligence in children of this age should be recognized as well. It is also advisable to conduct a study that will allow revealing in more detail the features of the social intelligence of 6-7-year-old children through the developed diagnostics of this type of intelligence, as well as presenting the characteristic features of this technique. This will enrich the diagnostic tools of educators, and, on the other hand, it will make it possible to outline promising prospects concerning the peculiarities of social intelligence in the process of preschool education.

Currently, there is certain scientific knowledge on the structure of the social intelligence of children and its diagnostics (O.Yu. Masyagina, L.A. Varlamova, E.V. Subbotsky, O.B. Chesnokova, I.Yu. Isaeva, L. F. Fatikhova, A. A. Kharisova, E. S. Mikhailova, E. F. Sayfutdiyarova, E. I. Nikolaeva, N. I. Kolcheva, and others) (Varlamova, 2016; Isaeva, 2011; Masyagina, 2010; Mikhaylova, 2007; Nikolaeva et al., 2013; Fatikhova \& Kharisova, 2010; Chesnokova \& Subbotsky, 2005). Analysis of the known methods for diagnosing the social intelligence of children (Varlamova, 2016; Yusupov's Diagnostics of. Empathy Level, n.d.; Mikhaylova, 2007; Nikolaeva \& Kolcheva, n.d.; Smirnova \& Kholmogorova, 2005; Guildford's Social Intelligence Test, n.d.; Fatikhova \& Sayfutdiyarova, 2013; Chesnokova et al., 2008) showed a wide variety of options for identifying the components of its structure, which is presented in different ways by different authors. At the same time, the methods addressed to children of school age are also used in preschool-age; they clearly require some modification since these methods are not always adapting to the age change. The mechanisms for assessing the results of the social intelligence testing in preschoolers also require improvement just because the very social intelligence is often replaced by the assessment of its particular components. Obviously, educators need convenient tools for 'measuring' social intelligence and its structural components, as a result of which the levels of this type of intelligence could be identified and described. This task requires developing a unified approach to the methodology for assessing social intelligence and the development of this methodology based on a combination of component levels of its structure. That would make it possible to determine the content of a differentiated approach to groups of children assigned to different levels of social intelligence in general, and different levels of development of individual structural components in particular. Still, it is necessary to develop appropriate diagnostics and familiarize teachers with its features since their articulated awareness will lead to the enrichment of the instrumental component of educational activity.

Therefore, the purpose of the study was to identify and describe the features of the social intelligence of 6-7-year-old children on the basis of the development and application of appropriate diagnostics of this type of intelligence. The tasks of the research included studying the theoretical aspects of the problem of social intelligence in children, the analysis of methods for measuring children social intelligence, the design and application of diagnostics of this type of intelligence and 
the description of its characteristics, and the analysis of the experimental results with the identification and description of all its peculiarities. The hypothesis of the study was expressed in the assumption that the development and application of diagnostics of the social intelligence in 67-year-old children will reveal its features, the consideration of which can be used as the basis for corresponding pedagogic work in preschool educational organizations.

The achievement of this goal is seen in the prospective widespread use in the process of preschool education of tools that will assist in measuring social intelligence and identifying its features in senior preschool children. This, in turn, will make it possible to develop a differentiated approach to children aged 6-7 and therefore sensitive for social development.

\section{METHODOLOGY}

The following methods were used in the course of the study: comparison, analysis, generalization of scientific views on the concept of 'social intelligence' and methods for assessing the social intelligence in children, simulation, project conception, summative assessment, method of statistical data processing (method of generalization of research findings), comparison, analysis, synthesis, generalization of experimental results and identification and description of its features.

The use of methods of comparison and analysis of classical and modern scientific views on the concept of 'social intelligence' provided theoretical support for subsequent experimental work. Comparison and analysis of a wide range of interpretations of the concept of 'social intelligence' such as the ability to understand and control people, acting wisely (Thorndike, 1920); the outcome of a personal social life, an indicator of self-sufficiency of personality (Bulgakova, 2017); part of social competence(Thorndike, 1920); a set of cognitive abilities that make it possible to understand people and situations of their interaction (Bobnev, 1978; Yudina, 2017; Yuzhaninova, 1984); particular personal and mental characteristics, manifested in interaction with society (Kunitsyna, 2001; Savenkov, 2005; Cantor, 1987); an integral part of general intelligence, performing the function of social interaction (Greenspan \& Driskoll, 1997; Sternberg, 1988); a complex construct that ensures human interaction with society (Luneva, 2015); the ability to 'realize and predict the outcome of the behavior of other people and oneself' (Molchanova, Chekanova, 2019); the area of interaction between cognitive and affective (Kosmitzki \& John, 1993); the ability to find optimal solutions, considering the interests of partners in a conflict situation and the peculiarities of their interpersonal relations (Shcherbakov, 2011) finally resulted in the definition of the concept of 'social intelligence of 6-7 year-old children'.

The use of the modeling method allowed developing a model of the relationship between consciousness and social intelligence and highlighting and describing the conceptual provisions of this model.

The participating children were conditionally divided into three groups: two with mono-age targeting and one with mixed targeting (diagnostics of social intelligence of school-age children; diagnostics of social intelligence of preschool children; diagnostics of social intelligence in preschool and primary school age) (Varlamova, 2016; Yusupov's Diagnostics of. Empathy Level, n.d.; Mikhaylova, 2007; Nikolaeva \& Kolcheva, n.d.; Smirnova \& Kholmogorova, 2005; Guildford's Social Intelligence Test, n.d.; Fatikhova \& Sayfutdiyarova, 2013; Chesnokova, Subbotsky, \& Martirosova, 2008). An analysis of the known diagnostic techniques for measuring social intelligence in children provided for the possibility of developing the concept of 'pedagogical diagnostics of the social intelligence of 6-7-year-old children'.

Further, a three-stage diagnostic technique for measuring social intelligence in 6-7-year-old children was developed based on the project concept. 110 children aged 6-7 and attending preschool educational organizations in the Lipetsk region took part in the ascertaining experiment. First stage: Diagnostics of the structure of social intelligence in 6-7 year-olds. 
This stage consisted of three parts: 1st part - self-regulation diagnostics; 2nd part - selfesteem; 3rd part - diagnostics of interpersonal interaction.

Part 1 (diagnostics of self-regulation in 6-7 year-olds) was conducted with the use of a modified 'Drawing a forester's house' technique (Ulenkova \& Lebedeva, 2002). The modification consisted in its adaptation to preschool age: specifying the goal, formulating criteria and indicators for assessing self-regulation, determining the levels of self-regulation, and developing a key to simplifying the processing of results. This modified technique was named 'Drawing a birdhouse' (Loshkareva, 2011).

The purpose of this method was to identify the features of self-regulation in 6-7-year-old children. Its implementation made it possible to determine the degree of memorization and understanding by the child of the rules of the proposed task, the nature of following the instructions, the formation of the organized activity skills, the adequacy of emotional reactions, and the ability to build an action plan.

The evaluation criteria were the compliance with the rules of the proposed assignment; the nature of the assessment of own performance; the final task achievement, measured by memorizing and understanding the rules of the proposed task; understanding the rules of the proposed task; following the instructions; skills in organized activities; the adequacy of emotional reactions; and building an action plan. The levels of self-regulation in senior preschool children were determined based on the developed criteria and indicators: high, average, and low.

Part 2 (diagnostics of self-esteem in 6-7 year-olds) was conducted using L.P. Ponomarenko's 'Tree' method (Ponomarenko, 2017). Its modification included adapting the task in reference to preschool children, formulating criteria, indicators, self-esteem levels, restructuring the key to the test, and modifying kids' drawing tasks. The modified technique was named the 'Cat's House' (Loshkareva, 2011). The process of the described method application implied the child's selection of two of his very own locations in the drawing, reflecting the real location in the present and the one predicted in the future. The ratio of the real and ideal position made it possible to determine the adequacy of self-esteem.

The criterion for the assessment was the position chosen by the child, indicating the ratio of the real and ideal position on the drawing task sheet.

Additional information on children's self-esteem of was obtained through the application of R.S. Nemova's 'What am I?' method (Nemov). The research was carried out in the form of a conversation, in which children assessed their personal qualities.

The criterion characterizing self-esteem was the degree of adequacy of ideas about oneself, indicating the nature of the child's ideas about own personal qualities.

Thus, the levels of self-esteem of senior preschoolers were determined based on the developed criteria and indicators as inflated, adequate, and deflated.

Part 3 (diagnostics of interpersonal interaction of 6-7 year-olds) was conducted by integrating two methods: 'Observation in the process of play' and 'Pictures' by E.O. Smirnova and V.M. Kholmogorova (2005).

The modification of the first technique included specifying the goal, determining the criteria and indicators for assessing children's interpersonal interaction, developing the content of the levels of this interaction, and developing the form of the research protocol. The purpose of applying this technique was to identify the interpersonal interaction of 6-7 year-olds.

The criteria for assessing interpersonal interaction were represented by initiativity and responsiveness, as well as the type of the state of mind (indicated by the activity in play; the nature of the child's response to the peers' proposals; and the adequacy of emotional responses in play).

The levels of interpersonal interaction of senior preschoolers were determined based on the developed criteria and indicators as high, medium, and low. The observation process was conducted during gaming activities for 2 days for each subject in natural conditions. 
Children's ideas on the norms of interpersonal interaction were identified using the 'Pictures' method by E.O. Smirnova and V.M. Kholmogorova (2005). Each child was asked to look at pictures depicting various life situations and describe what he/she would do in the place of the offended character. The evaluation criteria were understanding the conflict depicted in the picture; constructiveness in solving a problem-based situation; and discretion in solving of a situation, indicated by the description of own actions in the proposed situation; justification of such actions, and frequency of reference to mentor's assistance.

The grounds for determining the final levels of social intelligence of 6-7 year-olds (high, medium, low) were determined based on the combination of the levels of self-esteem, selfregulation, and interpersonal interaction. The assessment was based on the prevalence of the 2 or 3 highest levels of the structural components of social intelligence over the lowest (see Tables 5-7).

The method of statistical data processing (method generalization of research findings) reflected the quantitative results of diagnostics of social intelligence and its structural components, in particular, levels and their ratios.

The use of methods of comparison, analysis, synthesis, and generalization of research findings allowed identifying and describing the peculiarities of diagnostics of social intelligence in 67-year-old children, along with some characteristics of this type of intelligence.

\section{RESULTS}

Revealing common components in the content of interpretations of the concept of 'social intelligence' (namely, the reflection of an individual's social behavior in interaction with surrounding persons (Sushkova \& Loshkareva, 2019)) made it possible to comprehend its structure, highlight the main components of social intelligence that are most significant for the period of senior preschool age, and develop the concept of 'social intelligence of 6-7-year-old children '. The latter is characterized by age peculiarities and featured by a developing ability to build communication and interaction with people, resolve conflict situations or prevent their occurrence based on an adequate assessment of own and partners activities, as well as own actions and conduct. 
Figure 1. Model of the relationship between consciousness and social intelligence.

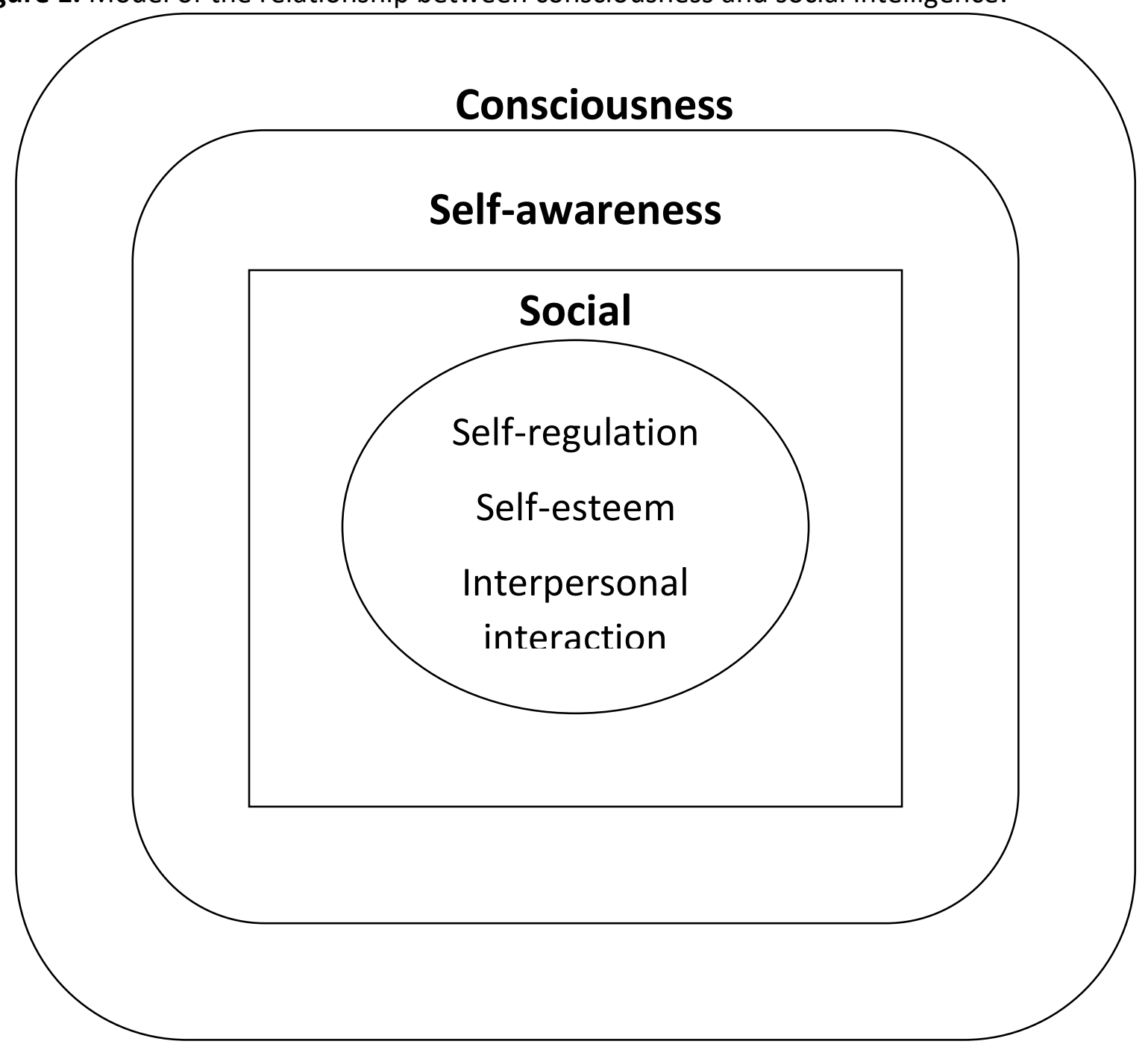

The analysis above contributed to the understanding of the structure of social intelligence by showing the interrelation of its components and their relationship with consciousness (Sushkova et al., 2020). A model of the relationship between consciousness and social intelligence was developed (see Figure 1), and the conceptual provisions that are the basis for its construction were described as follows:

1. Consciousness (the highest mental level of a person's reflection of reality) is structured by a number of abilities: reflexive ability (conscious commitment for self-cognition, including own psyche); mental representation and perception of reality (volitional control of mental processes); reflection in speech (verbal reproduction of mental operations through language); communicative ability (transferring information to others through language); intellectual ability (rules, logical operations, concepts aimed at processing and storing information about oneself and surrounding environment) (Sushkova et al., 2020).

2. Initially, self-awareness is superficial and focused on the external world; the child perceives it with the senses. Then goes the beginning of the development of reflection; at about three years old, the child begins to realize himself as an object of knowledge. The transition from emotional communication with the mother to object-oriented activity, playful or educational, allows bringing self-awareness to a higher level; by the age of seven, it results in an awareness of one's social ego. Thus, self-awareness turns out to be the last genetic characteristic of consciousness; its formation is largely determined by the child's communication and objective 
actions. Self-awareness is a person's self-perception which regards all the inherent personal qualities (Nemov). Self-awareness (reflexivity) allows a person to 'stay open' to his inner world.

3. One of the important structural components of consciousness is self-regulation - 'the process of managing own psychological and physiological states, as well as actions' (Nemov, p. 676). The level of self-regulation is determined by the will, the development of which presupposes the transformation of involuntary mental processes into voluntary and the development of control over one's behavior (Nemov). Self-regulation manifests itself at the age of 2 or 3 , and the will begins to manifest itself most actively in adolescence.

4. Another important structural component of social intelligence is self-esteem - 'a person's assessment of own qualities, advantages, and disadvantages' (Nemov, p. 676). It dtermines the social adaptation of the personality, and its level has a significant impact on mental development. Poor self-esteem manifests itself in an increased level of anxiety, fear, low assessment of inherent abilities, insufficient vigor of actions, and escape behavior. People with inflated self-esteem have the highest regard for their abilities; however, they may act recklessly in difficult situations, which lead to unpredictable results. Reasonable self-esteem allows a person to critically evaluate own abilities, thus solving problems deliberately and without unnecessary emotions. Self-esteem appears in a growing child usually by the age of four, being a result of the transition from ideas on self-image to self-perception (Kunitsyna, 2001). Children, evaluating the actions of others, begin to establish causal relationships. Differentiated self-esteem is formed by the age of seven; the family also plays an important role in this process. The manifestation of parental love forms positive selfesteem in children, while rejection provokes the opposite.

5. Self-regulation and self-esteem influence the development of interpersonal interaction: the process of direct or indirect influence of the subjects on each other, generating their mutual conditioning and interrelationship (Interaction // Academic Psychological Encyclopedia). The components of interpersonal interaction are represented by communication (the outer side of interpersonal interaction), attitude (attribution of an inner emotional meaningful thought about the object), and joint activity (the link between communication and attitude). The completeness of the manifestation of interpersonal interaction with all its components depends on age and features of personal development. According to the stages of personality development (Age periodization by Erickson), the factors of social development at the age of 5-11 are the child's interaction with society, acknowledgment of the others' point of view; understanding the norms, rules, and models of conduct (including the ones demonstrated by parents); assessments of the actions of others; and system of parental control.

6. Due to physiological and age-related peculiarities, self-esteem, self-regulation, and interpersonal interaction are characterized by various ratios of the degree of formation. These components of the structure of social intelligence of senior preschool children are interrelated. Selfregulation, as a result of the manifestation of will (begins at the age of 2-3), performs the function of controlling one's behavior and emotions. Self-esteem, which manifests itself in a child at the age of 4 , depends on the nature of control over the emotions and behavior. Self-esteem and selfregulation are a prerequisite for the formation of the ability to build constructive interpersonal interaction based on the ability to resolve or avoid conflicts.

Thus, the components of social intelligence appear to be in a substantive and structural relationship. These components, in conjunction, determine the content of social intelligence, which is an element of self-awareness and, therefore, one of the abilities of human consciousness.

The reliance on the developed concept of 'social intelligence of 6-7-year-old children' and the model of the relationship between consciousness and social intelligence, as well as comparison and analysis of methods for measuring the social intelligence of children, allowed defining the concept of 'pedagogical diagnostics of the social intelligence in 6-7-year-old children'. Pedagogical diagnostics of social intelligence in children of a given age is a set of measures aimed at identifying 
and assessing the components of the structure of social intelligence (self-regulation, self-esteem, interpersonal interaction) and determining its levels based on a combination of the corresponding levels of these components. The content of such diagnostics includes goals, methods, criteria and assessment indicators, levels, diagnostic procedures, stimulus material, forms of registering the results, and the very results themselves, which, in conjunction, allows identifying both the features of the structural components of social intelligence and the peculiarities of social intelligence in general.

As a result of the study, the features of the designed diagnostics of the social intelligence of 6-7 year-olds were identified and described. These include 1) sequential staging, 2) integrity (incorporation of modified methods into its content, along with single and multiple methods used at different stages), 3) combinativity of the levels of social intelligence components in determining the final level.

The results of diagnostics of the structural components of social intelligence in senior preschoolers are presented in Tables 1-7.

Table 1. Results of diagnostics of self-regulation of children aged $6-7$ years

\begin{tabular}{|c|c|c|c|c|}
\hline \multirow{6}{*}{ 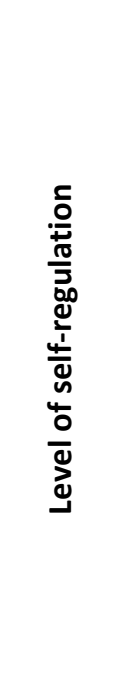 } & \multirow{4}{*}{$\begin{array}{c}\text { Total number of } \\
\text { participants }\end{array}$} & \multicolumn{3}{|c|}{ Method type } \\
\hline & & \multicolumn{3}{|c|}{ "Drawing a house for a bird" } \\
\hline & & \multicolumn{3}{|c|}{ Criteria and indicators for evaluating self-regulation } \\
\hline & & $\begin{array}{l}\text { compliance with the rules } \\
\text { of the proposed task } \\
\text { (memorizing and } \\
\text { understanding the rules of } \\
\text { the proposed task; } \\
\text { following the instructions) }\end{array}$ & $\begin{array}{l}\text { the nature of } \\
\text { evaluating your } \\
\text { work (the } \\
\text { adequacy of } \\
\text { emotional } \\
\text { reactions) }\end{array}$ & $\begin{array}{l}\text { achieving the goal } \\
\text { (skills of organized } \\
\text { activity; building an } \\
\text { action plan) }\end{array}$ \\
\hline & \multirow{2}{*}{$\begin{array}{l}\text { Number ( } \%) \text { of } \\
\text { subjects corresponding } \\
\text { to the level of self- } \\
\text { regulation }\end{array}$} & & & \\
\hline & & \multicolumn{3}{|c|}{$\begin{array}{l}\text { Number (\%) of participants corresponding to the level by criteria and } \\
\text { indicators }\end{array}$} \\
\hline High & $36 \%$ & $90 \%$ & $100 \%$ & $100 \%$ \\
\hline Average & $33 \%$ & $70 \%$ & $80 \%$ & $70 \%$ \\
\hline Low & $31 \%$ & $20 \%$ & $50 \%$ & $10 \%$ \\
\hline
\end{tabular}

Table 1 shows that the levels of self-regulation in 6-7 year-olds are contrastless: approximately the same number of children belongs to low, average, and high level groups.

$31 \%$ of the participants were attributed to the low level of self-regulation. This group was characterized by insufficient memorization and understanding of the rules of the proposed task, followed by the lack of organized activity skills and difficulties in planning. Also, the children of this group had manifested some lack of adequacy in emotional reactions when assessing their own performance - half of the children liked their drawing; the rest resorted to a negative assessment.

$33 \%$ of the participants were attributed to the average level of self-regulation. These were the children that demonstrated the formation of the skills of organized activity and the ability to build an action plan. During the course of performance, the children respected the rules proposed in the process of completing the task; they named 2-3 rules while discussing the drawing, were able to catch and realize their mistakes (with some teacher's assistance), and in most cases responded positively to a friend's request for help. However, in some cases, they refused to help a friend or just demonstrated such intention ('Ok, then. I will help', 'I will help, but only a little'). Most of the 
children rated their work positively. 7 participants showed dissatisfaction with the obtained results due to missing some details, the impossibility of taking into account all the rules, and insufficient conditions (sheet format) to accommodate all tasks.

$36 \%$ were attributed to a high level of self-regulation; most of them demonstrated the formation of the skills of organized activity and the ability to build an action plan. In the process of completing the tasks, the children respected all the proposed rules; named 4-5 of them while discussing the drawing, and were able to catch and realize their mistakes. The analysis of children's works showed that the participants followed all the rules, and the drawings were colorful and bright. Evaluating their work, all children demonstrated the adequacy of emotional response.

Table 2.The results of self-esteem diagnostics in 6-7-year-old children

\begin{tabular}{|c|c|c|c|c|c|}
\hline \multirow{8}{*}{$\begin{array}{l}\text { Self- } \\
\text { esteem } \\
\text { level }\end{array}$} & \multirow{4}{*}{$\begin{array}{l}\text { Total number of } \\
\text { participants }\end{array}$} & \multicolumn{4}{|c|}{ Method type } \\
\hline & & \multicolumn{3}{|c|}{ 'Cats House' } & 'What am I?' \\
\hline & & \multicolumn{4}{|c|}{ Self-esteem assessment criteria } \\
\hline & & \multicolumn{3}{|c|}{ Chosen position } & Degree of self-perception adequacy \\
\hline & \multirow[t]{2}{*}{110} & & & & \\
\hline & & \multicolumn{4}{|c|}{ Indicators } \\
\hline & \multirow[t]{2}{*}{$\begin{array}{c}\text { Number (\%) of } \\
\text { participants attributed } \\
\text { to one or another level } \\
\text { of self-esteem }\end{array}$} & \multicolumn{3}{|c|}{$\begin{array}{l}\text { the ratio of real and ideal } \\
\text { positions (the choice of } \\
\text { spatial location on the } \\
\text { worksheet) }\end{array}$} & $\begin{array}{l}\text { the nature of the child's ideas about } \\
\text { own personal qualities }\end{array}$ \\
\hline & & \multicolumn{4}{|c|}{$\begin{array}{l}\text { Number (\%) of participants corresponding to the level by criteria and } \\
\text { indicators }\end{array}$} \\
\hline Adequate & $36 \% / 34 \%$ & $20 \%$ & $80 \%$ & $0 \%$ & $95 \%$ \\
\hline Inflated & $34 \% / 36 \%$ & $100 \%$ & $0 \%$ & $0 \%$ & $30 \%$ \\
\hline Low & $30 \% / 30 \%$ & $10 \%$ & $10 \%$ & $80 \%$ & $10 \%$ \\
\hline
\end{tabular}

The self-esteem of children, as well as self-regulation, is distinguished by a contrastless character: each level of self-esteem was assigned with approximately the same number of children volunteered for the experiment.

Application of the 'Cat's House' method revealed $30 \%$ of the participants with low selfesteem. These children most often chose a low level of real and ideal positions. Still, there were cases of choice of middle and high levels of the ideal position, which testifies to the desire for adequate self-esteem and striving to change child's beliefs about oneself.

$34 \%$ of the participants identified with inflated self-esteem preferred the choice of high spatial real and ideal positions of the character in the task.

$36 \%$ of participants identified with adequate self-esteem have chosen the average level of real and ideal spatial positions, or a high level of real and the average level of the ideal positions, which indicates the presence of subtle desire to normalize own self-esteem in these group of children.

According to the results of the application of the 'What am I?' method, $30 \%$ of participants had low self-esteem. These children tend to underestimate themselves, which was manifested by answers 'No', 'I do not know' and 'no response'. A limited number of participants in this group described their personal qualities as 'good, kind, honest' but without any comments, which indicates a lack of self-perception.

$36 \%$ of the participants had inflated self-esteem. They called all the positive qualities without hesitation and quite undifferentiated, which testifies to the overestimation of oneself. Only $30 \%$ of children called themselves 'hardworking, good, honest', but without mentioning any other qualities, which testifies to the insufficient degree of self-perception adequacy. 
$34 \%$ of the participants had adequate self-esteem; they manifested quite reasonable ideas about themselves and their personal qualities in deliberated responses with detailed explanations. For example, most of the children did not consider themselves to be hardworking or answered 'sometimes', explaining their response as 'I feel sick', 'I don't want to', 'Mom does it for me', 'I will do that if asked to', etc. Also, not all children described themselves as 'honest', arguing that 'sometimes it is necessary', 'I cannot tell the truth' or 'then they may punish me.' $5 \%$ of participating children stated that they are not always kind, explaining their answer with 'when they punish me', 'because (someone) took my toy', 'when (someone) act badly, one should not be kind, but evil and punish back', etc.

Table 3. Results of interpersonal interaction diagnostics in 6-7-year-old children

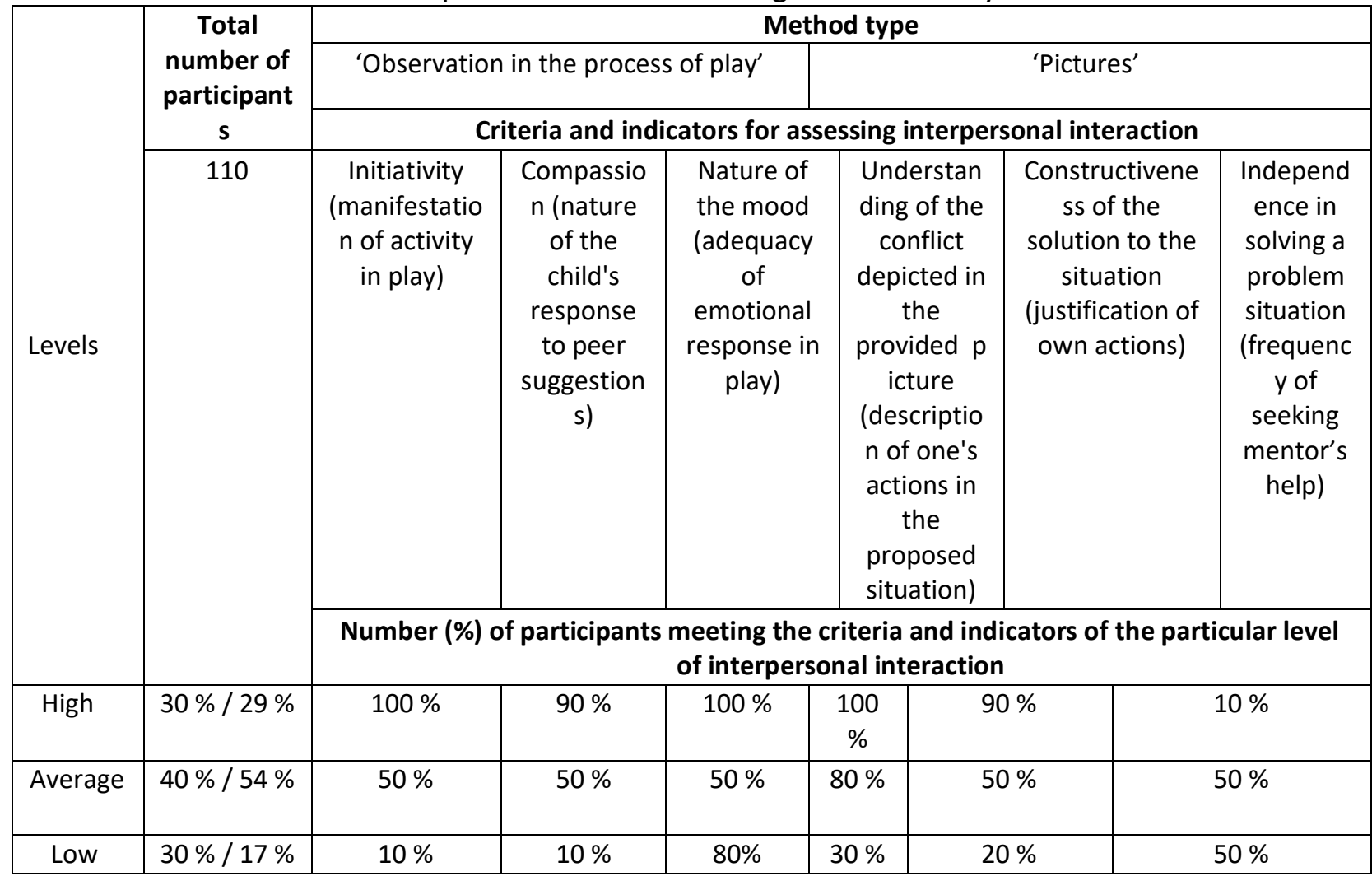

Table 3 shows that the levels of children's interpersonal interaction are not sharply contrasting in terms of quantitative indicators, although the number of children attributed to the average level is slightly higher.

According to the results of the application of the 'Observation in the process of play' method, $30 \%$ of the participants had a low level of interpersonal interaction. Children of this group preferred to play alone and rarely showed activity in play. The nature of the child's response to peer suggestions in this group is characterized by the predominance of passive following other children. Emotional reactions are unstable with a predominance of depressed mood.

Half out of $40 \%$ of the participants identified with an average level of interpersonal interaction manifested some uncertainty in attracting other children to play. Speaking of following other children, participants of this group manifested both active and passive roles in equal proportions. Also, frequent mood changes were noted in emotional responses to play.

$30 \%$ of the participants manifested a high level of interpersonal interaction. Children of this group actively attracted their peers to the game, displaying perseverance and initiative and offering various options for interaction, thus demonstrating quite some festive mood. The overwhelming majority of the participants in this group responded to the initiative of their peers with pleasure, 
actively picking up their ideas and actions. The degree of adequacy of emotional reactions in play was expressed in children's consistently positive moods.

$17 \%$ of the participants of the group surveyed with the 'Pictures' method manifested a low level of interpersonal interaction. An analysis of the degree of understanding of the conflict depicted in the picture showed that most of the children found it difficult to answer or turned to an adult for help, which indicates the lack of independence in solving the problem-based situation. It was also noted when assessing the constructiveness in solving a situation that children preferred isolated types of activity, giving answers with aggressive content. Overall, the children of this group had an unformed understanding of the norms of interpersonal interaction.

Most of 54\% attributed to the average level of interpersonal interaction demonstrated an understanding of the conflict depicted in the picture. Half of the children chose aggressive methods of conflict resolution; the rest resorted to the help of adults. Only one of the proposed situations was fully and correctly resolved.

$29 \%$ of the participants were classified as having a high level of interpersonal interaction. They were able to independently and constructively resolve the conflict depicted in the picture, describing the correct options for actions. When solving a problem situation, children showed quite some persistence in trying to teach the guilty character the consequences of his negative behavior.

The general results of diagnostics of the components of social intelligence structure in 6-7year-old children are shown in Table 4.

Table 4. Levels of social intelligence components in 6-7-year-old children

\begin{tabular}{|c|c|c|c|}
\hline Levels & Self-regulation & Self-esteem & Interpersonal interaction \\
\hline High & $36 \%$ & $36 \%$ & $30 \%$ \\
\hline Average & $33 \%$ & $34 \%$ & $50 \%$ \\
\hline Low & $31 \%$ & $30 \%$ & $20 \%$ \\
\hline
\end{tabular}

The data in Table 4 show that all three levels of self-esteem and self-regulation at the age of 6-7 are either identical in number or have minimal differences. Half of the participants (50\%) were attributed to the average level of interpersonal interaction, although only $33 \%$ showed an average level of self-esteem and 34\% - an average level of self-regulation. This testifies to the fact that high and low levels of these structural components of social intelligence do not distract some children from reaching the average level of interpersonal interaction.

Based on the results of diagnostics of self-regulation, self-esteem, and interpersonal interaction, as well as the combination of the levels of these structural components, the final levels of social intelligence of 6-7-year-old children were set as high, average, and low (see Tables 5-7).

Table 5. High level of social intelligence in 6-7-year-old children

\begin{tabular}{|l|c|c|c|c|}
\hline $\begin{array}{c}\text { Combinations of levels of } \\
\text { development of structural } \\
\text { components of social } \\
\text { intelligence }\end{array}$ & $\begin{array}{c}\text { Level of self- } \\
\text { regulation }\end{array}$ & $\begin{array}{c}\text { Level of self- } \\
\text { esteem }\end{array}$ & $\begin{array}{c}\text { Level of } \\
\text { interpersonal } \\
\text { interaction }\end{array}$ & $\begin{array}{c}\text { High level of } \\
\text { development of } \\
\text { structural } \\
\text { components in } \\
\text { quantitative (\%) } \\
\text { results }\end{array}$ \\
\hline $\mathbf{1}^{\text {st }}$ combination & High & Adequate & High & \multirow{2}{*}{$40(36 \%)$} \\
\hline $2^{\text {nd }}$ combination & Average & Adequate & High & High \\
\hline $3^{\text {rd }}$ combination & Low & Inflated & & \\
\hline
\end{tabular}

A high level of development of social intelligence in senior preschool children was revealed in 40 (36\%) participants. 
Table 6. Average level of social intelligence in 6-7 year-old children

\begin{tabular}{|c|c|c|c|c|}
\hline $\begin{array}{l}\text { Combinations of levels of } \\
\text { development of structural } \\
\text { components of social } \\
\text { intelligence }\end{array}$ & $\begin{array}{l}\text { Level of self- } \\
\text { regulation }\end{array}$ & $\begin{array}{l}\text { Level of self- } \\
\text { esteem }\end{array}$ & $\begin{array}{l}\text { Level of } \\
\text { interpersonal } \\
\text { interaction }\end{array}$ & $\begin{array}{c}\text { Average level of } \\
\text { development of structural } \\
\text { components in } \\
\text { quantitative (\%) results }\end{array}$ \\
\hline $1^{\text {st }}$ combination & Average & Inflated & Average & \multirow{4}{*}{$36(33 \%)$} \\
\hline $2^{\text {nd }}$ combination & Average & Adequate & Average & \\
\hline $3^{\text {rd }}$ combination & Low & Adequate & Average & \\
\hline $4^{\text {th }}$ combination & High & Inflated & Average & \\
\hline
\end{tabular}

An average level of development of social intelligence in senior preschool children was revealed in $36(33 \%)$ participants.

Table 7. Low level of social intelligence in 6-7 year-old senior preschool children

\begin{tabular}{|l|c|c|c|c|}
\hline $\begin{array}{c}\text { Combinations of levels of } \\
\text { development of structural } \\
\text { components of social } \\
\text { intelligence }\end{array}$ & $\begin{array}{c}\text { Level of } \\
\text { self- } \\
\text { regulation }\end{array}$ & $\begin{array}{c}\text { Level of self- } \\
\text { esteem }\end{array}$ & $\begin{array}{c}\text { Level of } \\
\text { interpersonal } \\
\text { interaction }\end{array}$ & $\begin{array}{c}\text { Low level of development of } \\
\text { structural components in } \\
\text { quantitative (\%) results }\end{array}$ \\
\hline $\mathbf{1}^{\text {st }}$ combination & Low & Deflated & Low & \\
\hline $\mathbf{2}^{\text {nd }}$ combination & Average & Deflated & Low & \multirow{2}{*}{$34(31 \%)$} \\
\hline $\mathbf{3}^{\text {rd }}$ combination & High & Deflated & Low & \\
\hline $\mathbf{4}^{\text {th }}$ combination & Low & Deflated & Low & \\
\hline
\end{tabular}

A low level of development of social intelligence in senior preschool children was revealed in 34 (31\%) participants.

Thus, the study showed that a little over one-third of the participants had a high level of selfregulation (36\%) and a high level of self-esteem (36\%); a little under a third had a high level of interpersonal interaction (30\%). As a result, a little over a third (36\%) of children were identified as having a high level of social intelligence. The average level of self-regulation was $33 \%$, the average level of self-esteem was $34 \%$, and interpersonal interaction - $50 \%$. The average level of social intelligence leveled up at $33 \%$.

The conducted study highlighted the features of the social intelligence of 6-7-year-old children. That includes its structure, expressed by a complex of variously interconnected components and a certain quantitatively contrastless hierarchy of levels.

\section{DISCUSSION}

The results of the study showed the possibility of developing the concept of 'social intelligence of 6-7-year-old children' based on highlighting the main components of its structure (self-regulation, self-esteem, interpersonal interaction), which are the most significant for the period of senior preschool childhood.

The development of this concept turned out to be necessary for the further buildout of a model of the relationship between consciousness and social intelligence, as well as the concept of 'diagnostics of the social intelligence in 6-7-year-old children.' Operating with these concepts formed the basis for the creation and application of diagnostics of social intelligence.

The conducted study allows describing in detail the development of diagnostics of social intelligence in senior preschool children, as well as the following features of its application:

1) it is possible and even advisable to modify the known methods for measuring social intelligence in accordance with the described structure of this type of intelligence and children's age-specific characteristics; 
2) the content of the developed diagnostics of social intelligence in 6-7-year-old children (see: Materials and methods) might be upgraded with the modified methods for diagnosing its components based on age-specific characteristics;

3) the content of modification of known methods for measuring social intelligence based on age-specific characteristics is represented by goals concretization and the development of criteria, indicators, and levels of structural components (social intelligence, task content alteration, and stimulus material);

3 ) it is advisable to determine the vector for the implementation of diagnostics of social intelligence in the form of successive stages of conducting diagnostic measures;

4) the integration of single and multiple methods at different diagnostic stages is not only possible but also methodologically justified;

5 ) the final level of social intelligence of a particular child (by diagnostics results) is determined by the combinativity of the levels of the components peculiar to this type of intelligence.

As a result, the use of methods of comparison, analysis, synthesis, and generalization of research findings allows asserting that a high level of social intelligence is resting upon the corresponding levels of self-regulation, self-esteem, and interpersonal interaction.

The average level of social intelligence is determined in accordance with the levels of selfregulation and self-esteem. Consequently, based on the combined diagnostics of only these two components, it is possible to make projections of the level of social intelligence of senior preschoolers.

The average level of interpersonal interaction was recorded in more than half of the participants, which allows stating the presence of a reciprocal relationship: attribution to low levels of self-esteem and self-regulation does not distract some children from rising to the average level of interpersonal interaction. The converse is also true: high levels of self-regulation and self-esteem sometimes do not provide for the same level of interpersonal interaction.

One-fifth of the participants (20\%) were attributed to a low level of interpersonal interaction, $31 \%$ - to a low level of self-regulation, and $30 \%$ - to a low level of self-esteem. Consequently, low levels of self-regulation (31\%) and self-esteem (30\%) also provide a correspondingly low level of social intelligence in general (31\%).

Overall, the results of the experiment showed that with adequate self-esteem, children are characterized by stable friendliness, a realistic assessment of their capabilities, and the desire to overcome difficulties. Children with low self-esteem exhibited signs of isolation, anxiety, and shyness. Inflated self-esteem played a key role in striving to take a leading position in all types of activity; the nature of the child's ideas on personal qualities, in this case, was expressed by the predominance of extremely positive assessments. Deflated and inflated self-esteem did not contribute to a realistic assessment of one's abilities and an adequate reflection of the opinions of other people.

It was also established that interpersonal interaction in most 6-7-year-olds is characterized by mood swings, lack of genuine understanding of problem-based situations and constructiveness of their resolution, lack of compassion, and the unstable manifestation of activity in play.

Analysis, interpretation, generalization, and systematization of scientific views on the concept of 'social intelligence' and its structure, as well as the results of the development and application of diagnostics, made it possible to identify and formulate the features of the social intelligence of 6-7-year-old children, determined by senior preschool age. These features include the following:

1. The social intelligence of 6-7 year-old children is characterized by structural properties, expressed by a complex of components (self-regulation, self-esteem, interpersonal interaction): 
- self-esteem in children of this age group is the ability to adequately assess themselves and other people, along with their own and other peoples actions and behavior,

- self-regulation in children of this age group is the ability to control their actions and conduct,

- interpersonal interaction in children of this age group is the ability to successfully build communication and interaction, resolve conflict situations, and prevent their occurrence.

2. The components of social intelligence appear to be in a substantive and structural relationship. These components in conjunction determine the content of social intelligence, which is an element of self-awareness and, therefore, one of the abilities of human consciousness.

3. Each component of social intelligence has its specific characteristics:

- self-regulation is distinguished by a certain severity of the degree of formation (in various ratios) of the skills to control own conduct (some children find it difficult to adjust to the given rules of behavior and actions; others easily follow, showing flexibility and integrity),

- self-esteem in 6-7-year-old children is manifested in various options for self-positioning in the world around (both the desire to take a more advantageous social position and attempts to 'drop off the radar' and remain unnoticed due to an incorrectly formed attitude towards oneself and others),

- interpersonal interaction of children is largely determined by self-regulation and selfesteem. These factors determine the nature of communication, the presence of anxiety, mood (swings), choice of topic for potential interaction, etc. At the same time, the content of interpersonal interaction manifests a fairly frequent inconsistency of ideas on the norms and rules of conduct and the actual behavior.

4. The social intelligence of 6-7-year-old children has a hierarchy of levels.

5. The quantitative expression of high, medium, and low levels of social intelligence in senior preschool age is quite contrastless (32\%, 38\%, and 30\%, respectively).

6 . At the age of 6-7, the features of social intelligence are determined by the specifics of the components of social intelligence structure. Consequently, there is a relationship between social intelligence and the components of its structure, which is expressed in the following:

- the levels of self-esteem and self-regulation are either identical in quantity or have minimal differences. At the same time, the quantitative indicators of high and medium levels of selfregulation and self-esteem may not correspond to the same indicators for interpersonal interaction (the level of interpersonal interaction in some children may remain average at any levels of selfesteem and self-regulation);

- high or low levels of social intelligence are ensured by corresponding levels of self-esteem and self-regulation.

Taking these features into consideration in the educational process in establishments of preschool or additional education may improve the effectiveness of pedagogical work on the development of the social intelligence of children assigned to different levels and, ultimately, on the effectiveness of their socialization.

\section{CONCLUSION}

Thus, as a result of the study, it became possible to expand the pedagogical information field by expanding and clarifying scientific information on the concept of 'social intelligence' in reference to the age of 6-7, along with the knowledge on the model of the relationship between consciousness and social intelligence. Also, the concept of 'pedagogical diagnostics of the social intelligence of 67-year-old children' was introduced into circulation; its content was developed, and the features of this diagnostics were identified and described. This provided theoretical support for the conducted experiment. 
The study showed the possibility and feasibility of developing diagnostics for measuring social intelligence in senior preschool age, which application allowed obtaining scientific data on the peculiarities of this type of intelligence in 6-7-year-old children.

Based on the experimental data obtained, these features were identified and described.

The findings may be used as the basis for the pedagogical work of educators and educational psychologists. The described features may also contribute to the meaningful interaction between the preschool educational organizations and the parents of attending children aimed at further determination of the strategy and tactics of pedagogical influences and interactions between the educator and children in the educational process. With the use of corresponding scientific information, the research findings will enable preschool educators to:

- operate with the concept of 'social intelligence of 6-7-year-old children';

- familiarize with the meaning of the concept 'diagnostics of social intelligence of 6-7-yearold children' and enrich their ideas on the content of this diagnostics;

- expand opportunities for measuring social intelligence based on diagnostics of its structure;

- evaluate the results of diagnostics of children's social intelligence through combining levels of components of this type of intelligence;

- enrich personal professional competencies with ideas on the features of social intelligence of senior preschool children.

Furthermore, the following promising areas for prospective research can be highlighted:

- concretization of each of the structural components of social intelligence in reference to different periods of preschool childhood;

- search for effective means of developing both social intelligence as a whole and individual elements of its structure;

- selection, analysis, generalization, and systematization of known, as well as a buildup of new effective methods for the development of social intelligence in preschool children;

- designing of individual and differentiated group work with children attributed to different levels of social intelligence in educational organizations.

Authors' Contributions: Loshkareva, O. N.: acquisition of data, analysis and interpretation of data, drafting the article; Sushkova, I. V.: drafting the article, critical review of important intellectual content. All authors have read and approved the final version of the manuscript.

Ethics Approval: Not applicable.

Acknowledgments: Not applicable.

\section{REFERENCES}

Age periodization by Erickson. Knowledge base. https://mamsila.ru/post/vozrastnaya-periodizaciya-eriksona

Antopolskaya, T., Zhuravleva, S., \& Baybakova, O. (2017). Social Communication as the Means of Preschool Children Education: Research and Development Opportunities. European journal of contemporary education, 6 (4), 636-644

Birknerova, Z., Juhas, J., \& Litavcova, E. (2009). Connection between Social Intelligence, Fear and Mobbing in School Environment. Sbornik prispevku: socialni procesy a osobnost. Clovek na ceste zivotem: Rizika, Vyzvy, Prilezitosti.

Bobneva, M.I. (1978). Social norms and regulations of behavior. Moscow: Academy of Sciences of the USSR, Institute of Psychology.

Bulgakova, V. (2017). Research on social intelligence and its importance for the development of sociology. IX International student's electronic scientific conference 'Student's scientific forum 2017'.

https://scienceforum.ru/2017/article/2017033075 
Burukina, O. (2012). Connotation - social intelligence. Cognitive linguistics issues. Derzhavin Tambov State University publishers, 2 (031), 125-130.

Cantor, N. (1987). Personality and social intelligence. New Jersey: Prentice-Hall, Inc. Englewood Cliffs.

Chesnokova, O., \& Subbotsky, E. (2005). Forms of manifestation of social intelligence in children: report at a seminar on developmental psychology. Lancaster, UK.

Chesnokova, O., Subbotsky, E., \& Martirosova, Y. (2008). Diagnostic methods of social intelligence in preschool and elementary school children. Journal 'Psychological Diagnostics', 3, 52-80.

Clinical psychology. B. D. Karvasarsky (ed.). St. Petersburg.

Erwin, P. (1993). Frienship and Peer Relations in childhood. Chichester, Willey.

Fatikhova, L., \& Kharisova, A. (2010). Workshop on psychodiagnostics of social intelligence in children of preschool and primary school age: teaching aid. MSU for the Humanities, Ufa branch publishers.

Fatikhova, L., \& Sayfutdiyarova, E. (2013). Description of social intelligence of children with intellectual disabilities. Special education.

Henderson, A., Gerson, S., \& Woodward, A. (2008). The Birth of Social Intelligence. Zero Three, May, 28(5), 1320. https://www.ncbi.nlm.nih.gov/pmc/articles/PMC4178946

Greenspan, S, \& Driskoll, J. (1997). The role of intellingence in a broad model of personal competence. In D.P. Flanagan, J.L. Genshaft (Eds.) Comtemporary intellectual assessment: Theories, tests and issues. New York: Guilford Press.

Guilford, J. (1959). Three sides of intelligence. Psychology of thought. A.M. Matyushkin (ed). Moscow.

Guilford, L., Morgan, B., \& Hemming, E. (2019). Gratitude, self-monitoring and social intelligence: A prosocial relationship? Current psychology, 1021-1032.

Guildford's Social Intelligence Test (n.d.). Encyclopedia of psychodiagnostics.

https://psylab.info/Тест «Социальный интеллект» Гилфорда

Hirosawa, T., Kontani, K., Fukai, M., Kameya, M., Soma, D., Hino, S., Kitamura, T., Hasegawa, C., An, K.M., Takahashi, T., Yoshimura, Y., \& Kikuchi, M. (2020). Different associations between intelligence and social cognition in children with and without autism spectrum disorders. Plus one, 15 (8).

Intelligence and executive function of school-age preterm children in function of birth weight and perinatal complication (2011). Applied neuropsychology-child.

Interaction (n.d.). Academic Psychological Encyclopedia. https://psychology.academic.ru/284/взаимодействие

Isaeva, I. (2011). Pedagogical support for the development of social intelligence in pre-school children: PhD thesis, author's abstract. Rostov on Don.

Kosmitzki, C., \& John, O. (1993). The implicit use of explicit conception of social intelligence. Personality and Individual Differences, 15 (1), 11-23

Krishchenko, E., Mozgovaya, N., \& Barsukova, O. (2019). Features of intelligence and creativity of the preschool children attending the preschool organizations of different kind. 13th International Technology, Education and Development Conference (INTED), Valencia, SPAIN: March 11-13, 2019. Series: INTED Proceedings, 1601-1606.

Kruszewska, A. (2018). Social and emotional competencies of future pupils of the 1st year of primary school society, integration, education. School pedagogy, preschool pedagogy. VOL. II, 2018. Series: Sabiedriba Integracija Izglitiba Society Integration Education,574-584

Kunitsyna, V. (2001). Social intelligence. Interpersonal relations: Textbook for higher. St. Petersburg.

Loshkareva, O. (2018). Validation of the pedagogical support model of the development of social intelligence in senior pre-school age children by means of physical culture. School of Young Scientists on the Problems of the Humanities: Materials of the All-Russian Scientific Conference, 61-67.

Luneva, O. (2015). Social Intelligence: the main problems and prospects of the research. Applied legal psychology, 1, 41-52. 
Maltese, A., Alesi, M., Alu, A., \& Giuseppa, M. (2012). Self-esteem, defensive strategies and social intelligence in the adolescence. International conference on education \& educational psychology. Series: Procedia Social and Behavioral Sciences, 69, 2054-2060.

Masyagina, O. (2010). Criteria for assessing the development of social intelligence in older preschoolers. Young Scientists Journal, 3 (14). https://moluch.ru/archive/14/1285/

Mikhaylova, E.S. (2007). Social intelligence: Concepts, models, diagnostics. St. Petersburg University publishers.

Molchanova, L., \& Chekanova, A. (2019). Features of the relationship of mental burnout and social intelligence of mothers in the upbringing of hearing-impaired children. Journal 'Perspectives of Science and Education', 3 (39), 290298.

Nagy, A., Kalmar, M., Beke, A. M., Graf, R., Horvath, E., Smirnova, E.O., \& Kholmogorova, V.M. (2005). Interpersonal relations of preschool children. Diagnosis, problems, correction. Moscow: VLADOS.

http://psychlib.ru/mgppu/smo/SMO-001-.HTM\#\$p1

Nemov, R. Psychology. Book 3. https://www.e-reading.club/bookreader.php/113908/Nemov Psihologiya. Kniga 3.pdf

Nikolaeva, E., \& Kolcheva, N. (2007). Peculiarities of the social behavior of children with intellectual disturbances. Siberian Pedagogical Journal. https://cyberleninka.ru/article/n/osobennosti-sotsialnogo-intellekta-detey-sdefitsitarnym-tipom-razvitiya

O'Connell, Michael \& Marks, \& Gary, N. (2021). Are the effects of intelligence on student achievement and well-being largely functions of family income and social class? Evidence from a longitudinal study of Irish adolescents. Intelligence, 84(101511).

Osterhaus, C., Putnick, D., \& Kristen-Antonow, S. (2020). Theory of Mind and diverse intelligences in 4-year-olds: Modelling associations of false beliefs with children's numerate-spatial, verbal, and social intelligence. British journal of developmental psychology, 38 (4), 580-593.

Ponomarenko, L. (n.d.). The 'Tree' method. https://nsportal.ru/nachalnayashkola/psikhologiya/2017/01/18/metodika-derevo-l-p-ponomarenko

Ruisel, I. (1992). Social intelligence - conception and methodological problems. Studia psychological, 34 (4-5), 281296.

Savenkov, A. (2005). Social intelligence as a problem of psychology of giftedness and creativity. Journal of Higher School of Economics, 2 (4), 98.

Savenkova, T. (2019). Development of social intelligence in senior pre-school children in the process of joint activity: PhD thesis, author's abstract. Moscow State Pedagogical University.

Selman, R. (1980). The development of interpersonal understanding. New York: Academic Press.

Shabanova, T., \& Zhurba, E. (2019). Research of social intelligence in elementary schoolchildren in the context of agerelated development tasks. Baltic humanitarian journal, 8 - 1 (26), 320.

Shcherbakov, S. (2011). Social intelligence and professional competence of engineers and technical workers. The Psychology. Journal of the Higher School of Economics, 8 (2), 148-155.

Silvera, D., Martinussen, M., \& Dahl, T. (2001). The Tromso Social Intelligence Scale, a self-report measure of social intelligence. Scandinavian journal of psychology, 42 (4), 313-319.

Skura, M., \& Swiderska, J. (2021). The role of teachers' emotional intelligence and social competences with special educational needs students. European journal of special needs education. Routledge journals, Taylor \& Francis LTD, Oxon, England. https://www.tandfonline.com/doi/full/10.1080/08856257.2021.1885177

Slovas, L., \& Cemanova, A. (2009). Social intelligence and self-control: Situational-relational context. Sbornik prispevku: Socialni procesy a osobnost, Clovek na ceste zivotem: Rizika, Vyzvy, PRILEZITOSTI.

Sternberg, R. (1988). The triarchic mind. New York: Viking.

Sudneva, O., Karaulova, O., \& Bogomaz, S. (2013). Social intelligence in the structure of personal potential and giftedness. Siberian Pedagogical Journal, 48, 118-126.

Sushkova, I., \& Loshkareva, O. (2019). Key issues of the development of social intelligence of children in foreign and domestic science. Journal 'Vestnik of Kostroma State University', 4, 94-98. 
Sushkova, I., Gerasimova, E., Pronina, A., \& Merenkova, V. (2020). Moral choice of children aged 6 to 8 in situations with ethnocultural context: what are the motives? Revista Turismo Estudos\&Práticas, S3, 82.

Sushkova, I., Loshkareva, O., \& Vlasova, G. (2020). Theoretical and methodological foundations of the development of social intelligence in preschool children by means of physical culture. Yelets State University publishers.

http://www.elsu.ru/uploads/files/2020-09/1601452663 uchebnoe-posobie-sushkova-loshkareva.pdf

Test: Assessment of self-control in communication (by Marion Snyder) (n.d.). Psychological workshop. https://psylist.net/praktikum/00048.htm

Thorndike, E. (1920). Intelligence and its uses. Harper's Magazine, 140, 228.

Turker, Y., \& Tanriogen, A. (2019). Effect of School Principals' Leadership Style on Teachers' Social and Emotional Intelligence. Pamukkale university journal of education, 51, 123-151.

Ulenkova, U., \& Lebedeva, O. (2002). Organization and content of special psychological assistance to children with developmental problems: A manual for students of higher education. Moscow: Academia.

Ushakov, D. (2004). Measuring Social Intelligence. Social intelligence: theory, measurement. D.V. Lyusin, D.V. Ushakov (eds.). Moscow: Institute of Psychology RAS publishers.

Varlamova, L.A. (2016). Peculiarities of Contemporary Schoolchildren's Social Intelligence. Journal 'Philological Sciences, Scientific Essays of Higher Education'.

Vasil'ova, K., \& Vyrost, J. (2004), Solving interpersonal situations as the indicator of social intelligence. Studia psychological, 46 (4),279-285.

Yudina, I. (2017). Social intelligence as one of factors successful development in adolescent age. Journal 'Modern Therapy in Psychiatry and Neurology'. https://cyberleninka.ru/article/n/sotsialnyy-intellekt-kak-odin-iz-faktorovuspeshnogo-razvitiya-v-podrostkovom-vozraste

Yuzhaninova, A. (1984). To the problem of diagnosis of social intelligence of a person. Issues in Psychological Assessment. Saratov University publishers.

Yusupov's Diagnostics of Empathy Level (n.d.). Psyera. https://psyera.ru/metodika-diagnostiki-empatii-i-myusupov9172.htm@14@

Received: 11 May 2021 | Accepted: 2 August 2021 | Published: 29 August 2021

This is an Open Access article distributed under the terms of the Creative Commons Attribution License, which permits unrestricted use, distribution, and reproduction in any medium, provided the original work is properly cited. 